\title{
Rituximab as a first-line preventive treatment in pediatric NMOSDs
}

\author{
Preliminary results in 5 children
}

\section{OPEN}

Giulia Longoni, MD

Brenda Banwell, MD

Massimo Filippi, MD

E. Ann Yeh, MD

Correspondence to

Dr. Yeh:

ann.yeh@sickkids.ca

\section{ABSTRACT}

Objective: No established therapeutic protocol has been proposed to date for childhood-onset neuromyelitis optica (NMO) spectrum disorders (NMOSDs). We report the response of 5 NMO immunoglobulin (Ig)G-positive pediatric cases to a standardized B-cell-targeted first-line immunosuppressive protocol with rituximab for prevention of relapses.

Methods: Retrospective observational cohort study.

Results: All patients included in the study showed disease remission after rituximab induction. Relapses always occurred in conjunction with CD19+ B-cell repopulation and appeared less severe than prior to treatment. At the end of follow-up, neurologic disability and MRI findings stabilized or improved in all the patients, with only minor and transient side effects. Oral steroid discontinuation was possible in all the patients.

Conclusions: Our protocol is well-tolerated and has provided encouraging results in terms of control of relapses and progression of disability. An early intervention with rituximab might affect the disease course in pediatric NMO-lgG-positive NMOSDs.

Classification of evidence: This study provides Class IV evidence that for children with NMOSDs, rituximab is well-tolerated and stabilizes or improves neurologic disability. Neurol Neuroimmunol Neuroinflamm 2014;1:e46; doi: 10.1212/NXI.0000000000000046

\section{GLOSSARY}

AQP4 = aquaporin-4; EDSS = Expanded Disability Status Scale; Ig = immunoglobulin; NMO = neuromyelitis optica; NMOSD $=$ neuromyelitis optica spectrum disorder

Neuromyelitis optica (NMO) spectrum disorders (NMOSDs) are a group of highly disabling inflammatory conditions of the CNS encompassing the definite form of NMO and a rapidly expanding spectrum of syndromes characterized by various combinations of symptoms and signs explained by the presence of lesions at sites of high aquaporin-4 (AQP4) expression. ${ }^{1}$

To date, the therapeutic management of pediatric NMOSDs has been largely based on Class IV evidence, and current practice follows studies of adult NMO (table 1 ). ${ }^{2}$ It is generally accepted that immunosuppression is necessary to prevent relapses and incremental attackrelated disability, but no established therapeutic protocol has been proposed to date.

Anti-AQP4 immunoglobulin (Ig)G (NMO-IgG), detected in 78\% of children with relapsing $\mathrm{NMO},{ }^{3}$ is considered to have a crucial role in the pathogenesis of the vast majority of these disorders, providing a strong rationale for the use of antibody-depleting therapies. An increasing number of studies have described the role of rituximab, a genetically engineered $\operatorname{IgG} 1$ targeting the circulating $\mathrm{CD} 20^{+}$B lymphocytes, in the long-term preventive immunotherapy of adult patients with NMOSDs. ${ }^{4-6}$ Rituximab may also ameliorate the course of these conditions in the pediatric population, ${ }^{7-10}$ but no standardized treatment approach has been proposed thus far.

From the Neuroimaging Research Unit, Institute of Experimental Neurology, and Department of Neurology, Division of Neuroscience (G.L., M.F.), San Raffaele Scientific Institute, Vita-Salute San Raffaele University, Milan, Italy; Department of Pediatrics (G.L., E.A.Y.), University of Toronto, and Division of Neurology (G.L., E.A.Y.), The Hospital for Sick Children, Toronto, Ontario, Canada; and Division of Neurology (B.B.), Children's Hospital of Philadelphia, University of Pennsylvania, Philadelphia, PA.

Go to Neurology.org/nn for full disclosures. Funding information and disclosures deemed relevant by the authors, if any, are provided at the end of the article. The Article Processing Charge was paid by the authors.

This is an open access article distributed under the terms of the Creative Commons Attribution-Noncommercial No Derivative 3.0 License, which permits downloading and sharing the work provided it is properly cited. The work cannot be changed in any way or used commercially. 


\begin{tabular}{|c|c|}
\hline Table 1 & $\begin{array}{l}\text { Immunosuppressive agents for } \\
\text { preventive therapy in neuromyelitis } \\
\text { optica }^{2}\end{array}$ \\
\hline \multicolumn{2}{|c|}{ Recommended } \\
\hline \multicolumn{2}{|c|}{ Azathioprine } \\
\hline \multicolumn{2}{|c|}{ Mycophenolate mofetil } \\
\hline \multicolumn{2}{|c|}{ Rituximab } \\
\hline \multicolumn{2}{|c|}{ Mitoxantrone } \\
\hline \multicolumn{2}{|c|}{ Methotrexate } \\
\hline \multicolumn{2}{|c|}{ Poor efficacy or harmful effects } \\
\hline \multicolumn{2}{|c|}{$\beta$-Interferons } \\
\hline \multicolumn{2}{|c|}{ Fingolimod } \\
\hline \multicolumn{2}{|c|}{ Natalizumab } \\
\hline
\end{tabular}

METHODS Primary research aim. The primary research aim was to report the clinical outcomes and the tolerability profile of a standardized B-cell-targeted immunosuppressive protocol with rituximab as the first-line treatment for long-term relapse prevention in NMOSDs in a cohort of pediatric patients (Class IV evidence).

Patients and methods. We performed a single-center retrospective analysis of consecutive patients followed at the Hospital for Sick Children, Toronto, Canada from 2009 to 2014 and included in the Hospital for Sick Children Demyelinating Disorders Database. We included children who (1) had an established diagnosis of $\mathrm{NMO}$ or $\mathrm{NMOSDs}^{1}$; (2) had a positive
NMO-IgG status (ELISA assay); (3) were treated with a standardized protocol using rituximab (induction therapy with $500 \mathrm{mg} / \mathrm{m}^{2}, 2$ doses 2 weeks apart; immunophenotyping with $\mathrm{CD} 19^{+}$B-lymphocyte count 2 weeks and 6 months after the second infusion and monthly thereafter; individualized retreatment timing at B-cell reconstitution [using a threshold of cell counts over $0.01 \times 10^{9} / \mathrm{L}$ ] or at a fixed maximum interval of 9 months from previous cycle, administered using the same induction course); and (4) had not received previous immunosuppressive treatments for relapse prevention. Patients were clinically and radiologically assessed at onset, 1 and 3 months from onset, every 6 months thereafter, and at the time of suspected clinical relapses; all the MRI scans were acquired on a $1.5 \mathrm{~T}$ scanner using nonstandardized sequences used in routine clinical practice.

Data analysis. Standardized demographic and clinical data points were collected on all patients using an established case report form, with subsequent chart review to confirm the data. MRI data were reviewed and assessed for the presence of worsening or improvements of T2/fluid-attenuated inversion recovery hyperintense and/or T1 hypointense lesions over time.

Standard protocol approvals, registrations, and patient consents. The study was approved by the local ethics committee as part of the ongoing Hospital for Sick Children Demyelinating Disorders Registry. Informed consent was obtained from all patients and caregivers.

RESULTS All the patients at our institution diagnosed with an NMOSD since 2009 were treated with rituximab according to the specified protocol and satisfied the inclusion criteria for the study. Table 2 details the clinical characteristics of the 5 included

\section{Table 2 Clinical characteristics}

\begin{tabular}{|c|c|c|c|c|c|c|c|c|c|}
\hline Patient & Sex & $\begin{array}{l}\text { Age at } \\
\text { onset, } y\end{array}$ & $\begin{array}{l}\text { Clinical features } \\
\text { at presentation }\end{array}$ & $\begin{array}{l}\text { Acute-phase } \\
\text { treatment }\end{array}$ & $\begin{array}{l}\text { MRI findings at } \\
\text { presentation }\end{array}$ & $\begin{array}{l}\text { Time from } \\
\text { symptom } \\
\text { onset } \\
\text { to rituximab } \\
\text { induction } \\
\text { therapy, mo }\end{array}$ & Side effects & $\begin{array}{l}\text { Time from rituximab } \\
\text { induction to B-cell } \\
\text { repopulation, mo }\end{array}$ & $\begin{array}{l}\text { Follow- } \\
\text { up, mo }\end{array}$ \\
\hline 1 & Female & 15.9 & $\begin{array}{l}\text { Intractable nausea } \\
\text { and vomiting with } \\
\text { severe progressive } \\
\text { encephalopathy and } \\
\text { coma }\end{array}$ & IVmp, PA, IVIg, P & $\begin{array}{l}\text { Deep WM/GM, optic } \\
\text { chiasm, brainstem; } \\
\text { LETM }\end{array}$ & 3.6 & $\begin{array}{l}\text { Facial rash; } \\
\text { mild transitory } \\
\text { leukocytopenia } \\
10 \text { days } \\
\text { after first } \\
\text { infusion }\end{array}$ & 6.0 & 27.7 \\
\hline 2 & Female & 10.9 & $\begin{array}{l}\text { Gait disturbances, } \\
\text { back pain }\end{array}$ & IVmp, PA, IVlg, P & $\begin{array}{l}\text { Subcortical and } \\
\text { periventricular WM } \\
\text { lesions; multicystic } \\
\text { LETM }\end{array}$ & 2.9 & $\begin{array}{l}\text { Urticaria, } \\
\text { transitory } \\
\text { hypotension }\end{array}$ & 5.3 & 16.7 \\
\hline 3 & Female & 11.6 & ON & IVmp, PA, IVlg, P & $\begin{array}{l}\text { Periventricular WM, } \\
\text { optic nerve, chiasm; } \\
2 \text { foci of subtle } \\
\text { intramedullary signal } \\
\text { change }\end{array}$ & 3.0 & None & NA & 19 \\
\hline 5 & Male & 17.0 & $\begin{array}{l}\text { Intractable hiccups, } \\
\text { nausea, and vomiting; } \\
\text { sinus bradycardia }\end{array}$ & IVmp, P & Area postrema & 3.2 & $\begin{array}{l}\text { Facial rash, } \\
\text { transitory } \\
\text { hypertension }\end{array}$ & 8.5 & 32.8 \\
\hline
\end{tabular}

Abbreviations: GM = gray matter; IVIg = IV immunoglobulin (2 g/kg over 2-5 days); IVmp = IV methylprednisolone (20-30 mg/kg daily for 3-5 days); LETM = longitudinally extensive transverse myelitis; NA = not applicable (therapeutic depletion up to 8.5 months after induction when retreated according to protocol); $\mathrm{ON}=$ optic neuritis; $\mathrm{P}=$ oral prednisone taper (starting at $2 \mathrm{mg} / \mathrm{kg}) ; \mathrm{PA}=$ plasmapheresis $(5-7$ treatments on alternate days); WM = white matter.

See text for further details. 
patients. The figure provides an overview of the clinical course and the treatment protocols. All the patients were treated with a standardized course of high-dose IV methylprednisolone $(20-30 \mathrm{mg} / \mathrm{kg}$ daily for 3-5 days) for the acute control of relapses, followed by an oral corticosteroid taper starting at $2 \mathrm{mg} / \mathrm{kg}$ (maximum $60 \mathrm{mg} /$ day). Those patients not showing signs of clinical improvement within 48-72 hours of beginning IV corticosteroid treatment (patients 1,2, and 3) were treated with additional plasmapheresis (5-7 treatments on alternate days, median volume exchanged 1:1-1:1.5) and/or IV immunoglobulin $(2 \mathrm{~g} / \mathrm{kg}$ over $2-5$ days, maximum $70 \mathrm{~g}$ ) as escalation therapy.

Relapse rate. Rituximab resulted in disease control in 3 patients who experienced catastrophic clinical manifestations with repeated relapses and steroidrefractory clinicoradiologic exacerbations prior to initiation of treatment (patients 1,2, and 5). All the relapses after rituximab initiation occurred before therapeutic $\mathrm{CD} 19^{+}$B-cell depletion (patient 2) or in strict conjunction with B-cell repopulation (patients 1 and 5). None of these patients required additional treatment for relapse control outside of IV corticosteroids. Patients 3 and 4 were relapse-free until the most recent follow-up. Oral steroid discontinuation was possible in all patients a median of 6.5 months (range 6.0-18.4) after rituximab initiation. Time to B-cell repopulation was variable, ranging from 5.3 to greater than 9.6 months after infusion (table 2).

Progression of disability. Median Expanded Disability Status Scale (EDSS) score in the 5 patients decreased

Figure Clinical course and overview of the treatment protocols

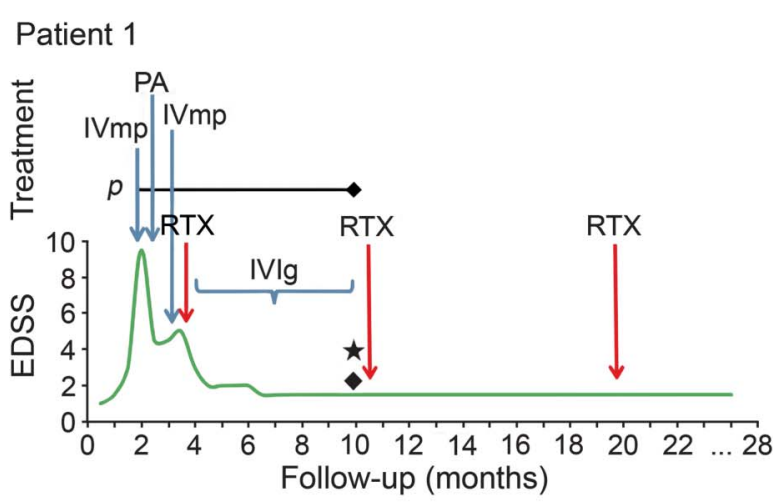

Patient 3

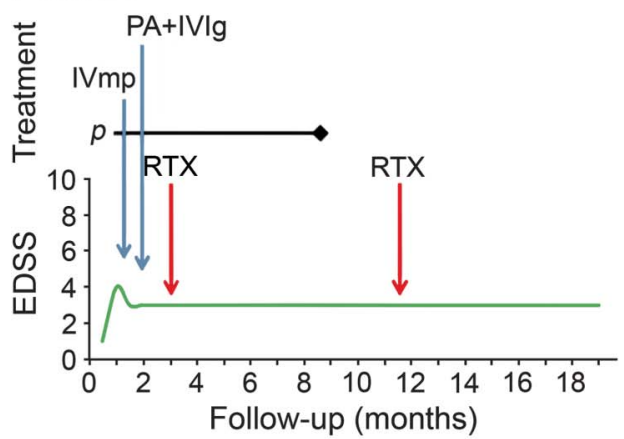

Patient 5

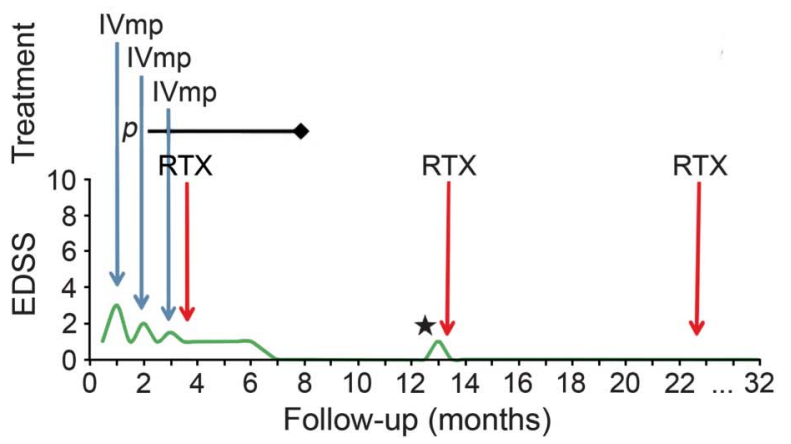

Patient 2

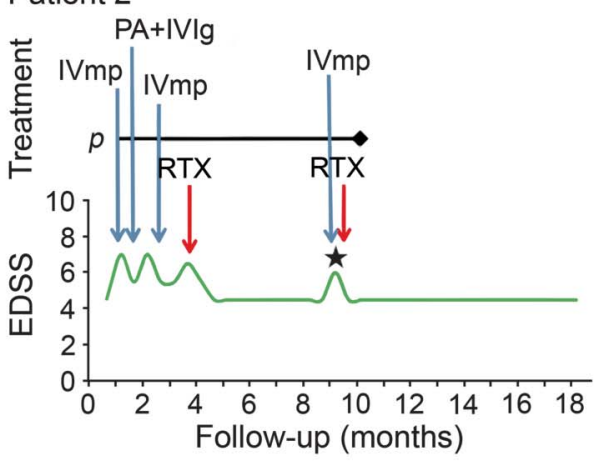

Patient 4

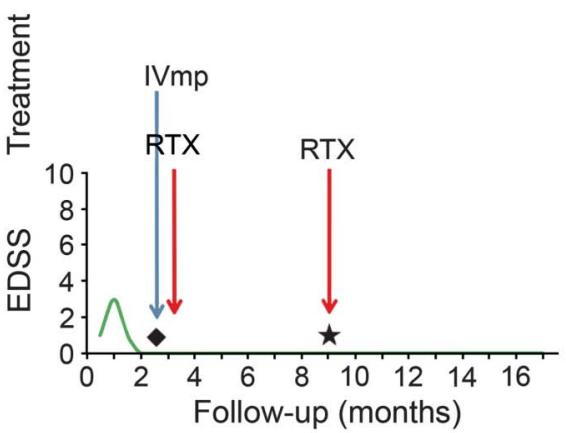

- = neuroradiologic evidence of new disease activity; $\star=C D 19+$ reconstitution. EDSS = Expanded Disability Status Scale; $\mathrm{IVIg}=\mathrm{IV}$ immunoglobulin; IVmp = IV methylprednisolone; $\mathrm{P}=$ oral prednisone taper; $\mathrm{PA}$ = plasmapheresis; $\mathrm{RTX}=$ rituximab. 
from 3.0 (range: $3-7$ ) at initiation of rituximab therapy to 2.0 (range: $0-4.5$ ) at 6 months from onset and 0.8 (range: $0-4.5$ ) at 12 months from onset. Of note, none of the 3 patients who relapsed showed the accrual of further permanent disability. Only 2 patients had permanent neurologic deficits at the last follow-up (patients 2 and 3; EDSS $=3$ due to impaired visual function and EDSS $=4.5$ due to chronic spinal cord syndrome, respectively).

Neuroimaging data. None of the patients showed any further extension of brain or spine lesions after rituximab-induced B-cell depletion (table 2).

Tolerability. No adverse events were reported during and after rituximab initiation outside of transient side effects at the time of infusion (table 2).

DISCUSSION Growing evidence in adult patients supports the safety and efficacy of rituximab for the chronic management of NMOSDs, ${ }^{4-6}$ but few published articles report its use in the pediatric population. $^{7-9}$ To the best of our knowledge, our study is the first to report a standardized approach to rituximab treatment for pediatric NMOSDs. Our protocol appears to be well-tolerated and has provided encouraging results in terms of control of relapses and progression of disability in pediatric NMOSDs.

Common practice includes repeated rituximab administration at fixed time intervals every 6-12 months. ${ }^{5,9}$ However, given the strict relationship between B-cell restoration and disease recurrence and the high interpersonal and intrapersonal variability of B-cell depletion (which can be sustained from a few months to more than a year), ${ }^{4-6}$ recently proposed approaches have suggested the individualization of retreatment frequency by regular monitoring of $B$ lymphocytes every 6-8 weeks. ${ }^{4,6}$ Advantages of such approaches include prompt detection of early B-cell reconstitution and minimization of cumulative doses of rituximab. In our cohort, immunophenotyping was performed 2 weeks after the second rituximab infusion, then 6 months afterwards, and monthly thereafter. Notably, disease relapses occurred in strict association with $\mathrm{CD} 19^{+} \mathrm{B}$-cell reconstitution in all cases. Because B-cell count assessment at a fixed interval of 6 months from previous infusion appeared to be insufficient to prevent 2 of the 3 relapses that occurred in our cohort after rituximab induction, our data support a more individualized monitoring approach with more frequent periodic immunophenotyping and retreatment as soon as B-cell reemergence is detected.

The early initiation of immunosuppressive treatment with rituximab may be of paramount importance in preventing further relapses and the accrual of permanent disability in NMO-IgG-seropositive cases (considered at high risk for developing a chronic relapsing disease ${ }^{3,7}$ ), challenging the current "step-up" approach, which tends to reserve rituximab for treatment-refractory cases. Unfortunately, the small sample size and the relatively short follow-up limit our results. Future safety and efficacy studies will be crucial in addressing these issues in the long term.

\section{AUTHOR CONTRIBUTIONS}

Drs. Longoni and Yeh had full access to all the data in the study and take responsibility for the integrity of the data and the accuracy of the data analysis. Study concept and design: Longoni, Yeh. Analysis and interpretation of data: Longoni, Yeh. Drafting of the manuscript: Longoni. Critical revision of the manuscript for important intellectual content: All authors. Study supervision: Yeh, Banwell.

\section{STUDY FUNDING}

No targeted funding reported. The funding organizations had no role in the design and conduct of the study; collection, management, analysis, and interpretation of the data; preparation or review of the manuscript; and decision to submit the manuscript for publication.

\section{DISCLOSURE}

G. Longoni reports no disclosures. B. Banwell has served on the advisory boards for Biogen-Idec, Sanofi, Eli Lilly, and Novartis; has received funding from Biogen-Idec, Merck-Serono, Teva Neuroscience, and Bayer; is on the editorial board for Neurology and Multiple Sclerosis and Related Disorders; has consulted for Biogen-Idec, Eli Lilly, and Sanofi; has spoken for Consortium of MS Centers; and has received research support from Canadian Institutes of Health Research, Multiple Sclerosis Society of Canada, Multiple Sclerosis Scientific Research Foundation, and National Multiple Sclerosis Society. M. Filippi has received funding from BayerSchering, Biogen-Idec, Merck-Serono, and Teva; is the Editor-in-Chief for Journal of Neurology; is an editorial board member for AJNR, BMC Musculoskeletal Disorders, Clinical Neurology and Neurosurgery, Erciyes Medical Journal, Journal of Alzheimer's Disease, Journal of Neuroimaging, Journal of Neurovirology, Lancet Neurology, Magnetic Resonance Imaging, Multiple Sclerosis, and Neurological Sciences; has consulted for BayerSchering, Biogen-Idec, Merck-Serono, Novartis, and Teva; is on the speakers' bureau for Bayer-Schering, Biogen-Idec, Merck-Serono, and Teva; and has received research support from Bayer-Schering, BiogenIdec, Merck-Serono, Novartis, Teva, Italian Ministry of Health, Fondazione Italiana Sclerosi Multipla, the Gossweiler Foundation, and Cure PSP. E.A. Yeh is on the editorial board for Neurology and has received research support from CIHR, PCORI, National MS Society, MS Society (Canada), Dairy Farmers of Ontario, and SickKids Innovation Fund. Go to Neurology.org/nn for full disclosures.

Received May 2, 2014. Accepted in final form October 13, 2014.

\section{REFERENCES}

1. Wingerchuk DM, Lennon VA, Lucchinetti CF, Pittock SJ, Weinshenker BG. The spectrum of neuromyelitis optica. Lancet Neurol 2007;6:805-815.

2. Kimbrough DJ, Fujihara K, Jacob A, et al. Treatment of neuromyelitis optica: review and recommendations. Mult Scler Relat Disord 2012;1:180-187.

3. Banwell B, Tenembaum S, Lennon VA, et al. Neuromyelitis optica-IgG in childhood inflammatory demyelinating CNS disorders. Neurology 2008;70:344-352.

4. Cree BA, Lamb S, Morgan K, Chen A, Waubant E, Genain C. An open label study of the effects of rituximab in neuromyelitis optica. Neurology 2005;64: 1270-1272.

5. Pellkofer HL, Krumbholz M, Berthele A, et al. Long-term follow-up of patients with neuromyelitis optica after 
repeated therapy with rituximab. Neurology 2011;76: 1310-1315.

6. Kim SH, Huh SY, Lee SJ, Joung A, Kim HJ. A 5-year follow-up of rituximab treatment in patients with neuromyelitis optica spectrum disorder. JAMA Neurol 2013;70: 1110-1117.

7. McKeon A, Lennon VA, Lotze T, et al. CNS aquaporin4 autoimmunity in children. Neurology 2008;71: 93-100.
8. Lotze TE, Northrop JL, Hutton GJ, Ross B, Schiffman JS, Hunter JV. Spectrum of pediatric neuromyelitis optica. Pediatrics 2008;122:e1039-e1047.

9. Mahmood NA, Silver K, Onel K, Ko M, Javed A. Efficacy and safety of rituximab in pediatric neuromyelitis optica. J Child Neurol 2011;26:244-247.

10. Beres SJ, Graves J, Waubant E. Rituximab use in pediatric central demyelinating disease. Pediatr Neurol 2014;51: 114-118. 


\section{Neurology \\ Neuroimmunology \& Neuroinflammation}

\section{Rituximab as a first-line preventive treatment in pediatric NMOSDs: Preliminary results in 5 children \\ Giulia Longoni, Brenda Banwell, Massimo Filippi, et al. \\ Neurol Neuroimmunol Neuroinflamm 2014;1; \\ DOI 10.1212/NXI.0000000000000046}

This information is current as of December 11, 2014

Updated Information \&

Services

References

Permissions \& Licensing

Reprints including high resolution figures, can be found at:

http://nn.neurology.org/content/1/4/e46.full.html

This article cites 10 articles, 0 of which you can access for free at: http://nn.neurology.org/content/1/4/e46.full.html\#\#ref-list-1

Information about reproducing this article in parts (figures,tables) or in its entirety can be found online at:

http://nn.neurology.org/misc/about.xhtml\#permissions

Information about ordering reprints can be found online: http://nn.neurology.org/misc/addir.xhtml\#reprintsus

Neurol Neuroimmunol Neuroinflamm is an official journal of the American Academy of Neurology.

Published since April 2014, it is an open-access, online-only, continuous publication journal. Copyright $($ ) 2014 American Academy of Neurology. All rights reserved. Online ISSN: 2332-7812.

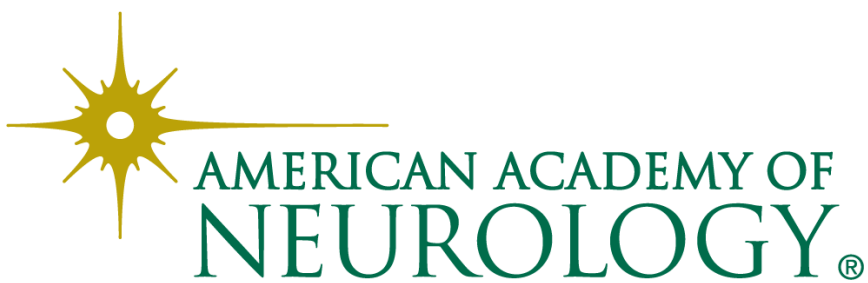

